EPiC Series in Engineering
Volume 3, 2018, Pages 1088-1095
HIC 2018. 13th International
Conference on Hydroinformatics

\title{
Microwave waste water meter: A new sensing principle for flow measurement in partially full pipes
}

\author{
Vasiliki Koutsospyrou $^{1}$, Martin Croft ${ }^{2}$, Ashraf El-Hamalawi ${ }^{1}$, Graham Sander ${ }^{1}$ \\ ${ }^{1}$ School of Architecture, Civil and Building Engineering, Loughborough University, Loughborough \\ LE11 3TU, U.K \\ ${ }^{2}$ Advanced Technology Innovation Centre, Loughborough University Science and Enterprise Park, \\ Loughborough LE11 3QF, U.K \\ Corresponding author: V.Koutsospyrou2@lboro.ac.uk
}

\begin{abstract}
This paper outlines the development of a novel, non-invasive microwave sensing system. A series of experimental investigations were undertaken to test the reliability of the sensors for determining the discharge in partially filled pipes under various hydraulic conditions.
\end{abstract}

Keywords: Flow measurement, microwaves, non-invasive

\section{Introduction}

The combined sewer network in the UK consists of approximately $347,000 \mathrm{~km}$ of pipes which collect and remove over 11 billion litres of waste water waste water from customers and a proportion of surface water during rainfall (OFWAT 2004). Approximately 30\% of the sewer pipes each year caused severe problems like flooding due to blockages, during the last decade. Research by Blanksby [3] has shown that the majority these flooding incidents from UK sewers were caused by blockages occurring in pipes of less than $300 \mathrm{~mm}$ diameter.

Until recently, most water companies in the UK had only post-reacted to these problems, an attitude that has raised major public and governmental health and safety concerns. As a result, water companies are now more willing to move into pro-active management by preventing sewer failure and as such a range of sewer monitoring systems are implied. Water companies expect that more sewer flow measurements will be required by the regulator in the future.

Sewage, in partially closed pipes, or in open channels, is a challenging measurement environment due to the range of very low flows at night to the occasional flooding from blockages. The cost and efficiency of the current sewer inspection technologies, which include CCTV and laser profiling to flow measurement methods of inspection is a problem for the water companies. Other non-intrusive less expensive methods of flow measurement are electromagnetic or laser Doppler meters, but these require either full pipes or clear fluid to operate reliably.

Microwave sensing is a rapidly developing technology which has been successfully used for various environmental and industrial applications including measurements of wave heights [4] and [5] and material moisture content [2]. The aim of this study is to assess the ability of a new microwave based 
meter to accurately measure volumetric flow rates within water and wastewater systems through a series of well-controlled experiments.

\section{Materials and methods}

The research is based on an experimental investigation of the influence of flow characteristics on microwave signals. The numerical analysis uses basic hydraulic theory of pipe flow to interpret the results. Data from sets of experiments was analysed, for consistency in the behaviour of the microwave sensors. Hydraulic equations were applied to the data, using MatLab, to determine flow rate and depth through the pipes for all experiments.

\subsection{Principle of operation}

The operation (Figure 1) of the microwave sensors is based on the Doppler radar principle whereby electromagnetic waves are emitted into the pipe, which are reflected by the surface of the water and then picked up by a receiver. The sensors use a dielectric resonator stabilised microwave FET (Field Effect Transistor) oscillator in the $\mathrm{X}$ band.

Figure 1:Principle of operation

1. Pipe: material non-metallic

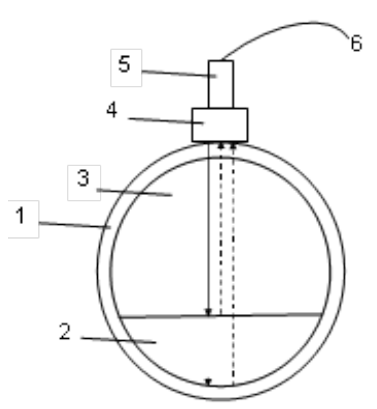

2. Water variable level

3. Head space-air

4. Waveguide interface to pipe

5. Microwave sensor

6. Cable or fibre interface to instrumentation electronics

\subsection{Experimental apparatus}

\subsubsection{University Hydraulics Laboratory Test Rig}

An experimental Test Rig (Figure 2) as been constructed at the Hydraulics Laboratory at Loughborough University. The experimental sewer system was made from $3 \mathrm{~m}$ lengths of 110 and $150 \mathrm{~mm}$ diameter PVC pipes. The inlet water was supplied through the pipes of $150 \mathrm{~mm}$ diameter where it entered a stilling tank and then flowed into a $5 \mathrm{~m}$ section made of $110 \mathrm{~mm}$ diameter pipes. The first $3 \mathrm{~m}$ after the stilling tank was made of translucent pipe in order for observations of flow depth to be made. At the end of the $5 \mathrm{~m}, 150 \mathrm{~mm}$ diameter pipes were again used to return the water to a sump. The total length of the sewer system was $21 \mathrm{~m}$ with the slope after the stilling tank set at 1 degree in line with the industry recommended minimum for wastewater pipes. However, by having the $5 \mathrm{~m}$ section supported on scaffolding at $1 \mathrm{~m}$ intervals (figure 2), it was also possible to adjust this slope away from 1 degree. A manual valve controlled the flow discharge through the whole system.

Figure 2:Test Rig 


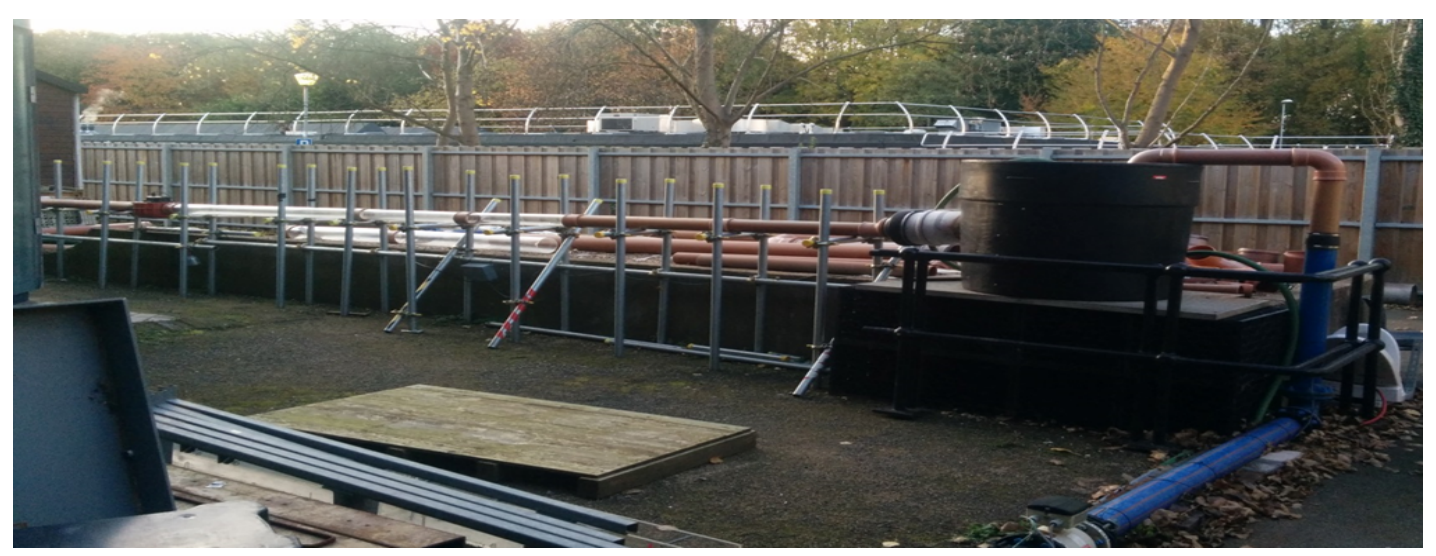

\subsubsection{Master meter-Electromagnetic flow meter}

A master meter (figure 3) was positioned before the stilling tank for comparing against the Microwave waste water meter (WWM) readings Calibration of the electromagnetic flow meter was done against the certified weigh tank (Avery ABC), having a BSI certification, with typical correlation results shown in Figure 4.

Figure 3:Electromagnetic flow meter

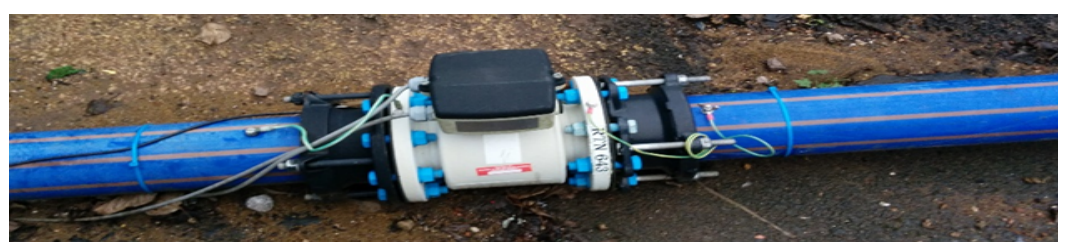

Figure 4: Correlation

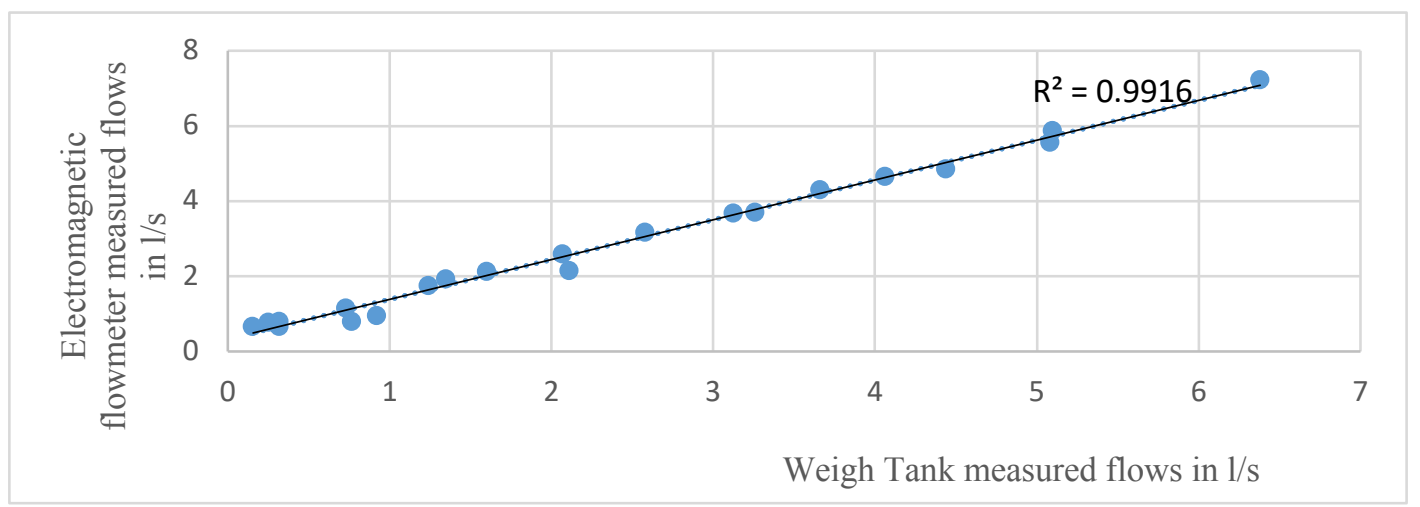

\subsubsection{Microwave Instrumentation}

The microwave instrumentation used in this work consisted of a microwave waste water meter, RAS and a laptop (figure 5) with software that controls the data acquisition and signal processing.

Figure 5:Microwave instrumentation

Figure 6:Microwave Waste Water Meter 

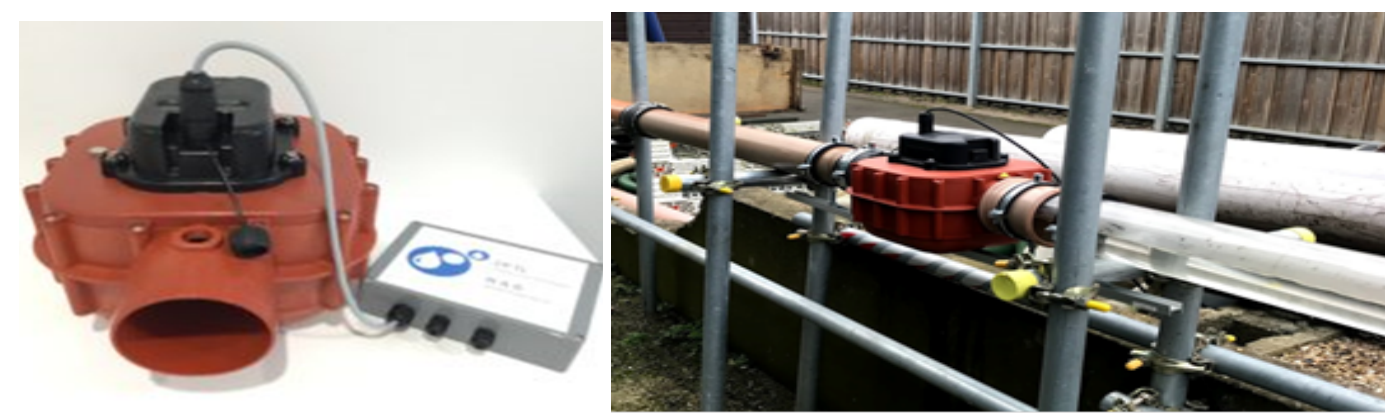

The WWM unit was installed in the laboratory test rig at the end of the $5 \mathrm{~m}$ translucent $110 \mathrm{~mm}$ diameter pipe sections (figure 6) for calibration and testing.

\subsection{Experimental procedure}

In order to achieve proper flow measurements, a number of aspects must be considered. These include selection of a suitable measurement section and knowledge of the hydrodynamic conditions at each potential measurement location.

\subsubsection{Testing}

A series of tests were devised:

- Static water level tests

- Placing the microwave waste water meter on two positions along the rig in relation to the outlet of the stilling tank i.e. $3 \mathrm{~m}$ and $6 \mathrm{~m}$.

- Changing the inlet conditions for a specific position i.e. flow calming.

\subsubsection{Flow conditions}

Waste water flow in sewers runs under gravity and their designs are for subcritical flow (Froude number $\mathrm{Fr}<1$ and Reynolds number $\mathrm{Re}<2000$ ) [6]. However, changes in pipe slope, diameter or roughness can occur and so there are regions of uniform flow interconnected with zones of non-uniform flow [6]. There are also many instances, when for example the system becomes overloaded due to heavy rainfall, where supercritical flow conditions occur, especially at flows around 21/s. The flow rates used ranged from $0.61 / \mathrm{s}$ to $121 / \mathrm{s}$ and corresponded to Froude numbers from 0.89 to 2.15 . To stop the formation of roll waves (for flow rates above 4.51/s and Froude numbers above 2) and eddies a honeycomb baffle was installed at the exit of stilling tank.

\subsubsection{Data collection-processing}

Data from the laboratory experiments was collected using a Remote Access Service (RAS) and transported via a Bluetooth to servers. Data from the Electromagnetic flowmeter was collected using a data logger and all data was processed with MATLAB software.

\section{Results and discussion}

\subsection{Static tests - proof of concept}

Static water level tests were performed to investigate the effects of the creation of ripples on the water surface on the microwave signal reflections. The setup is shown in Figure 7.

Figure 7:Static tests set up

Figure 8:Static test results 

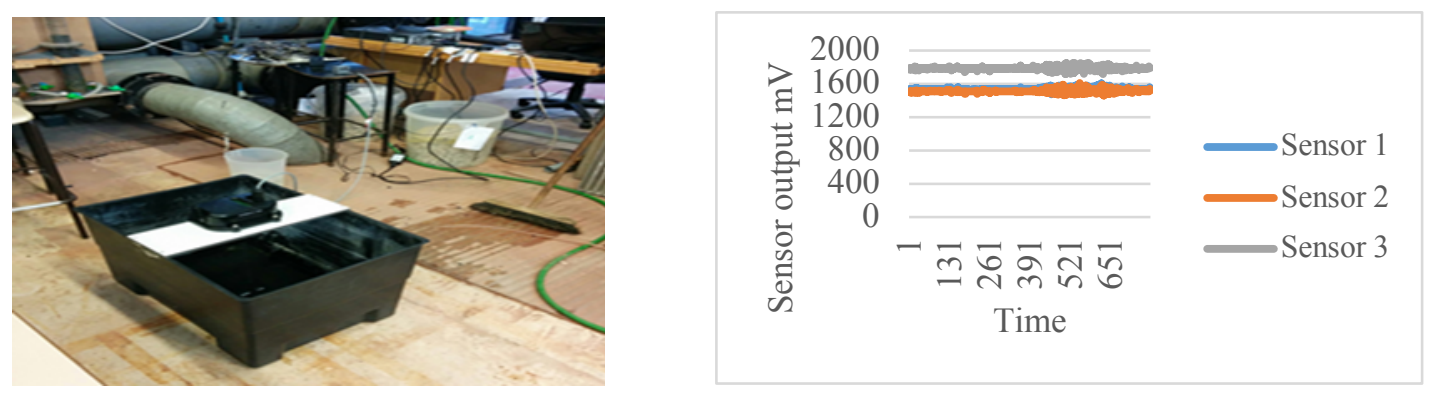

As it is obvious from Figure 7 that when ripples were created on the surface of the water (at time stamp 430), the signal was affected, and noise was observed. A fast time response of the sensors with disturbances in water level is clearly evident.

\subsection{Effect of the meter position from the stilling tank on the microwave signal}

According to water meter manufacturers, the length for positioning a flow meter from any inlet should be at least 5 times the pipe diameter. However, Durst et al. (2005) [9] provided an analytical relationship for correlating this length with the Reynolds number for laminar pipe flow and showed that the optimum position can be calculated using

$\frac{L}{D}=\left[(0.619)^{1.6}+\left(0.567 R_{e}\right)^{1.6}\right]^{1 / 1.6}$

resulting in a required distance of $2 \mathrm{~m}$ for placing the microwave meter. Therefore, we decided to initially place the sensor at $3 \mathrm{~m}$ from the stilling tank.

\section{- Initial position of the MWWM at 3 meters from inlet -no flow calming}

It was evident that for this initial position of the WWM noise patterns are higher in amplitude and the microwave signal range widely dispersed. This strongly suggested that the sensor needed to be further downstream. We therefore integrated the gradually varying flow equation in the downstream direction from the stilling tank to determine the distance to where normal depth occurs. The calculation showed that the minimum distance that the WWM must be positioned, in order for the readings not to be affected by disturbances from the stilling basin is at least $4 \mathrm{~m}$. Consequently, we next tried positioning the microwave sensor at $6 \mathrm{~m}$.

- $\quad$ MWWM 6 meter from inlet -no flow calming

Figure 9:Microwave waste water readings (0.8-101/s)

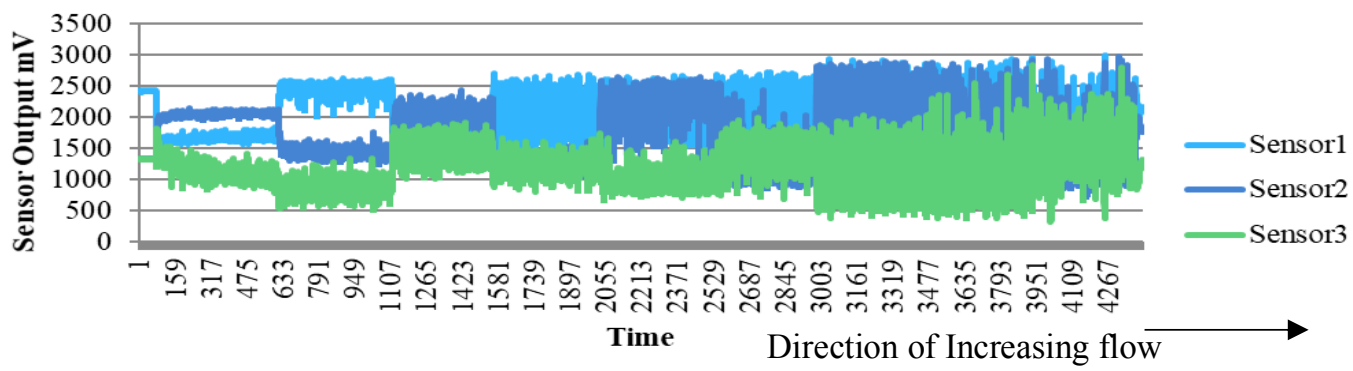




\section{- MWWM 6 meter from inlet -with flow calming}

Figure 10:Microwave waste water meter readings (0.8-12 1/s)

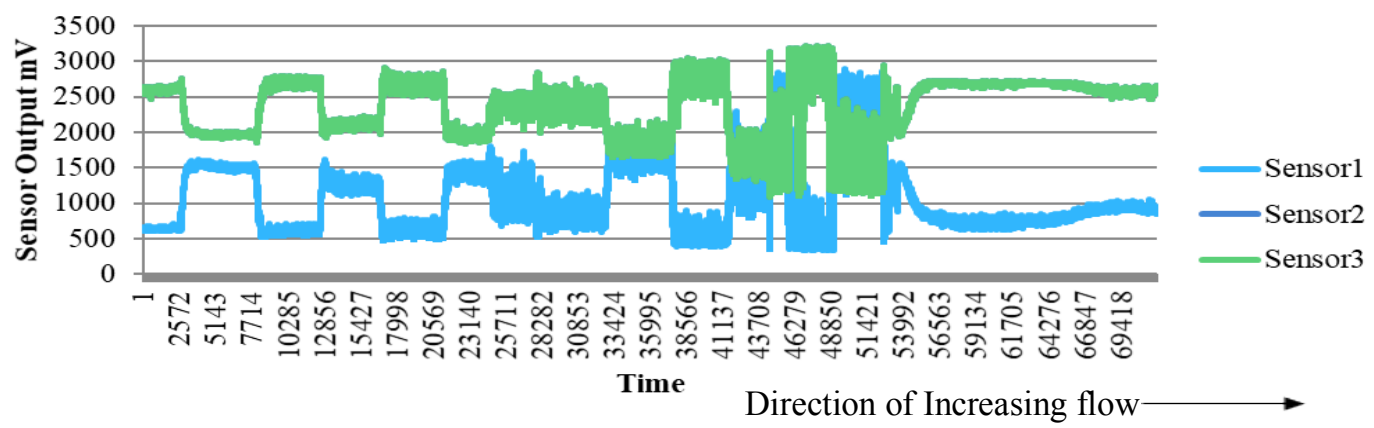

An initial and tentative comparison between figure (10), where flow calming techniques are introduced, and figure (9) where the presence of turbulence is evident, shows that the signal generated by the WWM is hugely affected by the hydraulic conditions in the pipe. The effect of turbulence on the sensor signal is reduced depending on its position on the test rig, which can then allow the sensor to better differentiate between the higher flows and thus improve the accuracy of the reading (figure 10). The noise patterns at low flow are usually smaller in amplitude and are usually produced by valves or pipe fittings [4].

\subsection{Assessing the reliability of the meter}

To assess the reliability of the microwave meter, we applied Manning's equation (2) to the measured data to estimate Manning's $n$ and see if this is in line with values in the literature.

$Q=\frac{1}{n} A R^{2 / 3} S^{1 / 2}$

\subsubsection{Manning Equation}

Manning's roughness coefficient is affected by the relative depth $(d / D)$, defined as the ratio of flow depth $d$ in the pipe to its diameter $D$. The relative Manning's roughness $\left(n / n_{\mathrm{f}}\right)$ is the ratio of Manning's $n$ for partial flow to full flow $\left(n_{\mathrm{f}}\right)$ [7], [1]. The equations of the relative Manning's coefficient as a function of the relative water depth for circular open channels as developed by Akgiray [1], Toews [11] and Bengtson in 2012, are:

$$
\begin{array}{lr}
n / n_{f}=1+\frac{(d / D)}{0.3} & 0 \leq d / D \leq 0.03 \\
n / n_{f}=1.1+(d / D-0.03)(12 / 7) & 0.03 \leq d / D \leq 0.1 \\
n / n_{f}=1.22+(d / D-0.1) 0.6 & 0.1 \leq d / D \leq 0.2 \\
n / n_{f}=1.29 & 0.2 \leq d / D \leq 0.3 \\
n / n_{f}=1.29+(d / D-0.3) 0.2 & 0.3 \leq d / D \leq 0.5
\end{array}
$$




$$
n / n_{f}=1.25+(d / D-0.5) 0.5 \quad 0.5 \leq d / D \leq 1.0
$$

In order to test the reliability of the sensors, Manning's $n$ was computed for each test, given the flow area for varying discharge, as measured from the microwave meter. These values were plotted against measured water depth values for each flow rate, for every test (coloured dots).

The calculated coefficients were then compared to literature values for PVC pipes as given by equations (3) - (8) and the results were plotted in Figure 11. The value of $n_{f}$ used in the calculations was 0.009.

Figure 11:Manning's n vs depth

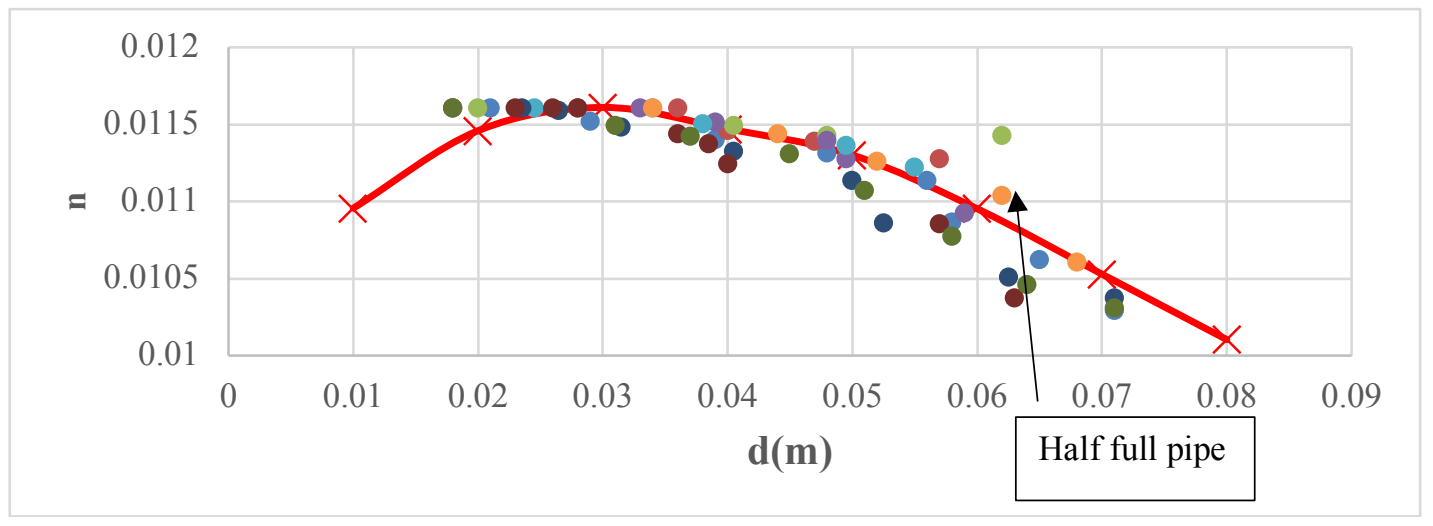

It is apparent that the computed results are in accordance with equations (3) - (8). Neale [10] stated that values of $n$ for PVC pipes range between 0.0095-0.015 with both Camp [7] and Chow [8] finding that for a pipe running partially full, $n$ varies from $0.0095-0.011$ and is greater than that of a full pipe, which is in agreement with the data shown in Figure 11.

\section{Conclusions}

The paper illustrated the potential of microwave sensing as a real-time monitoring platform for flow in a sewer network. This ongoing research has reinforced the importance of a fundamental understanding of the hydraulics to achieve a practical system which yields accurate measurements. It was concluded that:

- The microwave meter has a fast response time that is capable of recording disturbances on the water level surface.

- Readings are affected by water turbulence.

- At this optimum position the meter gives reliable results even at higher flows i.e. 9 1/s.

\section{References}

[1]Akgiray, Ö., 2014. Explicit solutions of the Manning equation for partially filled circular pipes Explicit solutions of the Manning equation for partially filled circular pipes. Canadian Journal of Civil Engineering.

[2]Bernou, C., Rebiere, D. \& Pistre, J., 2000. Microwave sensors : a new sensing principle. Application to humidity detection., Sensors and Actuators, Microwavepp.88-93.

[3]Blanksby, J., Khan, A. and Jack, A. (2002) Assessment of cause of blockage of small diameter sewers. Proc. Int. Conf. On Sewer Operation and Maintenance. ISBN 1851432132. 
[4]Boon, J.D., Heitsenrether, R.M. \& Bushnell, M., 2009. Microwave-Acoustic Water Level Sensor Comparisons : Sensor Response to Change in Oceanographic and Meteorological Parameters.

[5]Boon, J.D., Heitsenrether, R.M. \& Iii, W.M.H., 2012. Multi-Sensor Evaluation of Microwave Water Level Measurement Error.

[6]Butler, D., Davies, J., "Urban drainage", Second Edition, Spon Press, 2004.

[7]Camp, T.R. 1946. Design of sewers to facilitate flow. Sewage Works Journal, 18(1), 3-16

[8]Chow, V.T., “Open channel hydraulics”, International edition, McGraw-Hill, 1973.

[9]Durst, F. et al., 2005. The Development Lengths of Laminar Pipe and Channel Flows. Journal of Fluids Engineering, 127(6), p.1154.

[10]Neale, L. C. and Price, R. E., Flow Characteristics of PVC Sewer Pipe. Journal of Sanitary Engineering Division, (Div. Proc. 90SA3), 109- 129, 1964.

[11]Toews J. S. and Clark S. P., "Relative Depth Effects on Corrugated Culvert Roughness", Journal of Water Resource and Protection, (4) (838-841), 2012. 